\title{
Is Australia free from direct-to-consumer advertising?
}

\author{
Agnes Vitry, Senior Lecturer, Quality Use of Medicines and Pharmacy Research Centre, \\ University of South Australia, Adelaide, and member of Healthy Skepticism
}

\section{Summary}

Direct-to-consumer advertising is the promotion of prescription medicines to the general public. It is legal in New Zealand and the USA where it is a very effective marketing strategy and is growing rapidly. Several studies have shown that direct-to-consumer advertising commonly contains misleading, inaccurate or unbalanced information. Direct-to-consumer advertising is not currently allowed in Australia, however drug companies can try to overcome the ban. They can do this by running disease awareness campaigns that indirectly promote their products, by supporting professional and patients' organisations and by sponsoring journalists. We need to develop strategies to counteract these campaigns and give all Australians access to unbiased, accurate and comprehensive information about their treatment options.

Key words: quality use of medicines, consumer information, drug industry.

(Aust Prescr 2004;27:4-6)

\section{Introduction}

Direct-to-consumer advertising is the promotion of prescription medicines to the general public. New Zealand and the USA are the only two countries in the Organisation for Economic Co-operation and Development (OECD) that allow direct-toconsumer advertising of prescription medicines. Direct-toconsumer advertising is not currently allowed under Australia's Therapeutic Goods Act, however the legality of direct-toconsumer advertising in New Zealand and the USA has significant implications for Australia. Australia and New Zealand are moving towards a common regulatory drug agency that will supervise the promotion of prescription medicines in both countries. Pharmaceutical manufacturers have also signalled that Australia's restrictions on direct-to-consumer advertising are one of the targets of the current US-Australia negotiations for a free trade agreement between the two countries. ${ }^{1}$

\section{Impact of direct-to-consumer advertising}

The impact of direct-to-consumer advertising on the New Zealand health system was reviewed during 2003 by a group including professors of general practice from all of New Zealand's four Schools of Medicine. ${ }^{2}$ Their report summarised the international evidence on the economic significance of direct-to-consumer advertising, its role in consumer education and its implications for medicine use and safety. It also included surveys of general practitioners' and consumers' views on direct-to-consumer advertising.

The review found that spending on direct-to-consumer advertising is growing exponentially. In the USA in 1995 US\$375 million was spent on direct-to-consumer advertising, rising to over US\$2.7 billion in 2001. This spending represented nearly one third of the total spending on drug promotion in the USA. There was a corresponding increase in sales of prescription drugs. Between 1999 and 2000 sales increased by US $\$ 20.8$ billion and the 50 medicines with the highest advertising budgets accounted for nearly half of this increase. These trends are mirrored in New Zealand. In 2001-02 four heavily advertised drugs accounted for almost a quarter of the increase in the dispensing of pharmaceuticals listed on the Pharmaceutical Schedule.

Patients' requests for medicines are a powerful driver of prescribing decisions. In New Zealand 69\% of the general practitioners who responded to a survey reported that they had been under pressure from their patients to prescribe advertised medicines, even if they felt that these medicines offered little added benefit over drugs they would normally use. ${ }^{2}$

Direct-to-consumer advertising commonly contains misleading, inaccurate or unbalanced information. In New Zealand a survey of three months of advertisements found that $31 \%$ of all direct-to-consumer advertisements, including five out of six television advertisements, were in breach of the Medicines Act. In the USA, between 1997 and 1999, 52\% of direct-to-consumer advertisements were found to be in violation of the Food, Drug and Cosmetics Act. A US survey showed that printed directto-consumer advertisements commonly failed to provide a quantitative description of a drug's benefits, but mainly included emotional appeals and tended to promote the medicalisation of normal health and minor illnesses. ${ }^{3}$ 
The New Zealand review concluded that direct-to-consumer advertising does not provide consumers with objective information on risks, benefits and options of treatment and is a serious risk to the sustainability of health systems. The reviewers have called for a ban of direct-to-consumer advertising in New Zealand. ${ }^{2}$ This is now under consideration. ${ }^{4}$

\section{De facto direct-to-consumer advertising in Australia}

In Australia, the Code of Conduct of Medicines Australia (previously the Australian Pharmaceutical Manufacturers Association) complements the legislative requirements and prohibits direct-to-consumer advertising. The Code has a number of loopholes, however, that allow companies to subvert the ban on direct-to-consumer advertising.

The Code of Conduct relies mainly on spontaneous complaints, and voluntary compliance by drug companies. Drug companies can advertise prescription products to the public until they get 'caught', if by chance somebody bothers to send a complaint to Medicines Australia. This happened last year when SanofiSynthelabo advertised their hypnotic zolpidem in the Qantas magazine in October 2002. A complaint was lodged, the company was found to have breached the code and was fined $\$ 50$ 000. In the meantime, the illegal advertisement may have been seen by thousands of Qantas travellers.

De facto direct-to-consumer advertising increasingly occurs in the form of advertisements about specific diseases and conditions, which do not mention the name of a drug, but may include the company name or their logo. For example, Roche has conducted an extensive advertising campaign for orlistat, which is marketed for weight loss. The campaign included television advertisements, advertisements in magazines, glossy brochures displayed in community pharmacies, a free call number and a web site (www.loseweightgainlife.com.au).

In this campaign the public was told the story of 'Linda' who took a 'life-changing decision' and states 'I spoke to my doctor about modern innovative approaches to weight loss. That was $18 \mathrm{~kg}$ ago!'. Other advertisements showed photos of Linda at the swimming pool and stated 'Two years on and Linda is 30 kilos lighter and a whole lot wiser'. Concurrent mailings to doctors inform them about the 'Lose Weight Gain Life Program' which is in its '3rd successful year' and includes reproductions of consumer advertisements and a letter with the logo 'Xenical Lose Weight. Gain Life'. The advertisements to consumers do not mention the name of the drug and so are not banned under the current Medicines Australia Code of Conduct. The benefits of orlistat are exaggerated as a systematic review of the clinical effectiveness of orlistat found that the mean weight loss observed with orlistat was only $3.2 \mathrm{~kg}$ more than with placebo after two years. ${ }^{5}$ The advertising campaign does not link with national initiatives, such as Active Australia, which encourage participation in physical activity. This campaign may raise false hopes in many people and may put general practitioners under great pressure to prescribe orlistat even if not clinically appropriate.

Sildenafil has also been the focus of extensive campaigns in Australia. Pfizer has indirectly promoted sildenafil by using celebrity endorsements in newspaper and television advertisements featuring the legendary soccer player Pelé urging men to consult a doctor about erection problems.

\section{Disease awareness campaigns}

Disease awareness campaigns can be used as a strategy to extend the boundaries of treatable illness and to expand markets for new products. ${ }^{6}$ Pharmaceutical companies are orchestrating campaigns by sponsoring professional or consumer groups, without revealing that they have initiated and financially supported them. For example, Merck Sharp \& Dohme has promoted finasteride with advertisements that urge balding men to see their doctor. At the same time the company orchestrated a campaign in the Australian media with experts suggesting that losing hair could lead to panic and other emotional difficulties, and could even have an impact on job prospects and mental well-being. It was not disclosed that the experts quoted were provided by the public relations firm in charge of the campaign. ${ }^{6}$

The Australian Consumers' Association recently reported on one of these disease awareness campaigns. ${ }^{7}$ The Healthy Weight Task Force was marketed as being the 'first ever network of primary healthcare professionals to have formed in response to the rising levels of excess weight and obesity in Australia'. The task force considered orlistat to be the most effective and appropriate form of weight loss. The findings and educational materials produced by the Healthy Weight Task Force were broadly promoted to the mainstream media and directly to general practitioners. What was not stated in any information provided by the Healthy Weight Task Force was that the pharmaceutical company, Roche, funded the project and that the recommended product was produced by Roche.

Another tactic used to promote media coverage of particular health issues is the sponsorship of journalists to attend conferences overseas. Pharmaceutical companies have also established journalism awards like the Eli Lilly award for 'excellence in journalism in the field of menopause'. ${ }^{8}$

Last year a media agency was even more innovative and won the national award in the 'best one-off media campaign' for Australia. Novo Nordisk had commissioned the agency to plan a campaign to increase the sales of a topical preparation of oestradiol. The agency devised a promotional campaign involving hairdressers. ${ }^{9}$ The address of a web site about painful intercourse was emblazoned in reverse on capes for women to wear in hairdressing salons. 


\section{Conclusion}

Like other commercial enterprises, drug companies focus on making profits, and this determines their priorities. They have been pressing governments to allow direct-to-consumer advertising. In 2002, they lobbied the European parliament to relax the European Union ban on direct-to-consumer advertising. However, the health ministers of the European Union rejected the proposed amendment in June 2003 following an intense counter-campaign organised by consumer and health professional organisations.

Drug companies are trying to get around the current ban in Australia by running disease awareness campaigns that indirectly promote their products and by sponsoring journalists, and professional and patients' organisations. Government agencies, health professional and consumer organisations concerned about the quality use of medicines in Australia need to develop a range of strategies on how best to counteract these campaigns. We also need to improve the public's access to unbiased, accurate and comprehensive information about the options for drug treatment.

E-mail: agnes.vitry@unisa.edu.au

\section{References}

1. Lokuge K, Denniss R. Trading in our health system? The impact of the Australia-US FreeTrade Agreement on the Pharmaceutical Benefits Scheme. Discussion Paper 55. Canberra:The Australia Institute; 2003.

2. Toop L, Richards D, Dowell T, Tilyard M, FraserT, Arroll B. Direct to consumer advertising of prescription drugs in New Zealand: for health or for profit? Report to the Minister of Health supporting the case for a ban on DTCA. New Zealand Departments of General Practice (Christchurch, Dunedin,
Wellington and Auckland Schools of Medicine); 2003. http://www.chmeds.ac.nz/report.pdf (cited 2003 Nov)

3. Woloshin S, Schwartz LM, Tremmel J, Welch HG. Direct-toconsumer advertisements for prescription drugs: what are Americans being sold? Lancet 2001;358:1141-6.

4. Burton B. New Zealand moves to ban direct advertising of drugs. News roundup. Br Med J 2004;328:68.

5. O'Meara S, Riemsma R, Shirran L, Mather L, ter Riet G. A rapid and systematic review of the clinical effectiveness and cost-effectiveness of orlistat in the management of obesity. Health Technol Assess 2001;5:1-81.

6. Moynihan R, Heath I, Henry D. Selling sickness: the pharmaceutical industry and disease mongering. Br Med J 2002;324:886-91.

7. Ballenden $\mathrm{N}$, Goddard M. The hard sell. Consuming interest (Australian Consumers' Association) 2003;94:6-9.

8. Sweet M. Sponsored journalism award shocks Australian media. Br Med J 2001;323:1258.

9. Bastian $\mathrm{H}$. Promoting drugs through hairdressers: is nothing sacred? Br Med J 2002;325:1180.

Conflict of interest: none declared

\section{Self-test questions}

The following statements are either true or false (answers on page 23)

1. Some consumer organisations receive funding from drug companies.

2. Direct-to-consumer advertising is not associated with increased prescribing of the advertised drugs.

\section{Medicines Australia Code of Conduct: breaches}

Medicines Australia (formerly the Australian Pharmaceutical Manufacturers Association) has a code of conduct to guide the promotion of prescription drugs in Australia., ${ }^{1,2}$

The report of the Code of Conduct Committee for 2003 says that 48 new complaints about drug promotion were received. Five complaints were withdrawn and some are unresolved, so the report details the assessment of 36 cases. $^{3}$

Most of the complaints came from rival pharmaceutical companies, but 11 came from health professionals, five were made by the Therapeutic Goods Administration and one by a consumer organisation. Seven complaints were found not to involve a breach of the Code of Conduct and one was dismissed by the Code of Conduct Appeals Committee. This leaves 28 complaints in which at least one breach of the Code was found (Table 1).

\section{Note}

The Medicines Australia Code of Conduct is available from: Medicines Australia

Level 1, 16 Napier Close

DEAKIN ACT 2600

Tel: (02) 62826888

Fax: (02) 62826299

Web site: www.medicinesaustralia.com.au

\section{References}

1. Roughead EE. The Australian Pharmaceutical Manufacturers Association Code of Conduct: guiding the promotion of prescription medicines. Aust Prescr 1999;22:78-80.

2. Medicines Australia. Code of Conduct. 14th ed. Canberra: Medicines Australia; 2003.

3. Medicines Australia. Code of Conduct Annual Report 2003. Canberra: Medicines Australia; 2003. 